\title{
Phosphodiesterase 5 Inhibition Improves Synaptic Function, Memory, and Amyloid- $\beta$ Load in an Alzheimer's Disease Mouse Model
}

\author{
Daniela Puzzo, ${ }^{1,3}$ Agnieszka Staniszewski, ${ }^{1}$ Shi XianDeng, ${ }^{2}$ Lucia Privitera, ${ }^{1,3}$ Elena Leznik, ${ }^{1}$ Shumin Liu, ${ }^{1}$ Hong Zhang, \\ Yan Feng, ${ }^{1}$ Agostino Palmeri, ${ }^{3}$ Donald W. Landry, ${ }^{2}$ and Ottavio Arancio ${ }^{1,2}$ \\ ${ }^{1}$ Department of Pathology and Cell Biology and Taub Institute for Research on Alzheimer's Disease and the Aging Brain, Columbia University Medical \\ Center, and ${ }^{2}$ Department of Medicine, Columbia University, New York, New York 10032, and ${ }^{3}$ Department of Physiological Sciences, University of Catania, \\ Catania 95125, Italy
}

Memory loss, synaptic dysfunction, and accumulation of amyloid $\beta$-peptides (A $\beta$ ) are major hallmarks of Alzheimer's disease (AD). Downregulation of the nitric oxide/cGMP/cGMP-dependent protein kinase/c-AMP responsive element-binding protein (CREB) cascade has been linked to the synaptic deficits after $\mathrm{A} \beta$ elevation. Here, we report that the phosphodiesterase 5 inhibitor (PDE5) sildenafil (Viagra), a molecule that enhances phosphorylation of CREB, a molecule involved in memory, through elevation of cGMP levels, is beneficial against the $\mathrm{AD}$ phenotype in a mouse model of amyloid deposition. We demonstrate that the inhibitor produces an immediate and long-lasting amelioration of synaptic function, CREB phosphorylation, and memory. This effect is also associated with a long-lasting reduction of $\mathrm{A} \beta$ levels. Given that side effects of PDE 5 inhibitors are widely known and do not preclude their administration to a senile population, these drugs have potential for the treatment of $\mathrm{AD}$ and other diseases associated with elevated $\mathrm{A} \beta$ levels.

\section{Introduction}

Alzheimer's disease (AD) is characterized by neuronal loss, extracellular senile plaques, and intracellular neurofibrillary tangles, leading to memory loss. Extensive literature suggests that $\mathrm{AD}$ begins as a synaptic disorder produced at least in part, by amyloid $\beta$ (A $\beta$ ) (Selkoe, 2002). Long-term potentiation (LTP), a cellular model of memory, and phosphorylation of c-AMP responsive element-binding protein (CREB), a transcription factor involved in memory, are reduced by $\mathrm{A} \beta$ (Vitolo et al., 2002). Interestingly, both nitric oxide (NO) donors and cGMP analogs counteract the $\mathrm{A} \beta$-induced impairment in LTP and CREB phosphorylation (Puzzo et al., 2005). Vice versa, genetic ablation of NO synthase 2 (NOS2) results in worsening of the AD phenotype in mice expressing mutated amyloid precursor protein (APP) (Colton et al., 2006), suggesting that upregulation of the NO pathway may be protective in $\mathrm{AD}$.

One effective way to upregulate the NO pathway is by increasing cGMP levels through inhibitors of phosphodiesterase 5 (PDE5), an enzyme expressed in several brain regions associated

\footnotetext{
Received Feb. 19, 2009; revised April 21, 2009; accepted May 18, 2009.

This work was supported by grants from the National Institutes of Health (NS049442 and R21AG027468). We thank Karen Hsiao-Ashe (University of Minnesota and Mayo Clinic, Rochester, MN) for providing the APP mice, Karen Duff (Columbia University) for providing the PS1 mice, Vincent Florio at ICOS Corporation (Bothell, WA) for providing IC354, and Rusiko Bourtchouladze (PsychoGenics, Tarrytown, NY) for helpful discussion and comments.

The authors declare no competing financial interests.

Correspondence should be addressed to Dr. Ottavio Arancio, Department of Pathology and Cell Biology and Taub Institute for Research on Alzheimer's Disease and the Aging Brain, Columbia University Medical Center, 630 West 168th Street, New York, NY 10032. E-mail: oa1@columbia.edu.

D0I:10.1523/JNEUROSCI.0864-09.2009

Copyright $\odot 2009$ Society for Neuroscience $\quad 0270-6474 / 09 / 298075-12 \$ 15.00 / 0$
}

with cognitive function, such as the hippocampus, cortex, and cerebellum (Van Staveren et al., 2003, 2004) (see also, for human brain, Gene Logic's ASCENTA System) (M. Sakurai, personal communication). Preclinical studies have shown that the selective PDE5 inhibitors sildenafil (Viagra; Pfizer) and vardenafil (Levitra; Bayer) raise hippocampal cGMP levels and improve memory in aged rats (Prickaerts et al., 2002a) and mice (Baratti and Boccia, 1999). Interestingly, the Food and Drug Administration (FDA) has recently approved the daily use of the inhibitor tadalafil (Cialis; Lilly) (see http://www.clinicaspace.com/news_ story.aspx?NewsEntityId = 82124). Moreover, PDE5 inhibitors are widely used to treat erectile dysfunction and pulmonary hypertension so that their side effects are known. Thus, it is possible that PDE5 inhibitors might be compatible with administration to a senile population such as AD patients. Based on these elements, in the present study, we have investigated whether PDE5 inhibition could exert beneficial effects against the $\mathrm{AD}$ phenotype of mice carrying both the mutant APP (K670N,M671L) and presenilin-1 (PS1; M146L), termed APP/PS1 mice.

\section{Materials and Methods}

Animals

Double transgenic mice expressing both the human APP (K670M: N671L) and PS1 (M146L) (line 6.2) mutations were compared with wildtype (WT) littermates. They were obtained by crossing APP with PS1 animals. To identify the genotype of the animals, we used the PCR on samples of the tail (Trinchese et al., 2004). The protocol was approved by the Columbia University Institutional Animal Care and Use Committee. The animals were maintained on a $12 \mathrm{~h}$ light/dark cycle (with light onset at 6:00 A.M.) in temperature and humidity-controlled rooms of the Columbia University Animal Facility. Food and water were available ad libitum. 


\section{Drug preparation}

Sildenafil was synthesized in six steps according to reported procedures (Terrett et al., 1996) (US Patent 5,346,901.1994) at the Core Facility of Organic Chemistry at Columbia University. Briefly, commercially available 2-ethoxybenzoic acid was converted to 2-ethoxybenzoyl chloride with thionyl chloride. Reaction of 2-ethoxybenzoyl chloride with 4-amino-1-methyl-3- $\mathrm{N}$-propylpyrazole-5-carboxamide yielded the amide in $90 \%$ yield. Cyclization of the amide using $\mathrm{NaOH}$ afforded pyrazolopyrimidinone in $77 \%$ yield. Chlorosulfonylation of the pyrazolopyrimidinone in chlorosulfonic acid, followed by reaction with $\mathrm{N}$-methylpiperazine provided sildenafil in $90 \%$ yield. Tadalafil was also synthesized at the Core Facility according to reported procedures (Daugan et al., 2003b). Briefly, D-tryptophan methyl ester reacted with piperonal under Pictet-Spengler reaction condition (TFA/CH2Cl2/MeOH), and the resulting product condensed with chloroacetyl chloride to provide acylated intermediate. Reaction of the intermediate with $N$-methyl amine provided tadalafil. Tadalafil was diluted in $0.1 \%$ DMSO. IC354 was a gift from ICOS Corporation.

\section{Drug administration}

Three-month-old APP/PS1 and WT mice were separated into four groups: APP/PS1 mice treated with vehicle, APP/PS1 mice treated with PDE inhibitor, WT mice treated with vehicle, and WT mice treated with PDE inhibitor. In one experimental series, we assessed the acute effects of PDE inhibition on synaptic dysfunction by perfusing hippocampal slices with sildenafil (50 nM), or tadalafil (50 nM), or IC354 (1 $\mu \mathrm{M})$ for $10 \mathrm{~min}$ before the theta burst. In a separate series of experiments, we also examined the acute effect of different concentrations of sildenafil to establish its minimal effective concentration. In the remaining experiments, we intraperitoneally injected sildenafil. For assessment of the short-term effects of sildenafil, the drug was given at a concentration of $3 \mathrm{mg} / \mathrm{kg}$ immediately after the training. This dose yields concentrations of $\sim 2.5$ $\mu \mathrm{M}$ cGMP in the hippocampus (Prickaerts et al., 2002b). In these experiments, we also established the minimal effective concentration of sildenafil and the minimal effective days of sildenafil delivery. For assessment of long-term effects, sildenafil was given daily by intraperitoneal injection at a concentration of $3 \mathrm{mg} / \mathrm{kg}$ for 3 weeks, and then treatment was stopped for $9-12$ weeks before behavioral testing. The minimal effective number of days of sildenafil delivery and the minimal sildenafil effective concentration that could still trigger long-term rescue of memory at 6 months were also studied. Contextual and cued fear conditioning was performed for $3 \mathrm{~d}$. Radial arm water maze (RAWM) was performed for 3 weeks. Morris water maze lasted $3 \mathrm{~d}$. Then, the animals were killed for electrophysiological recordings.

To decide the time of administration of sildenafil in the short-term effect experiments, we performed a series of preliminary studies in which the inhibitor was injected intraperitoneally at $5 \mathrm{~min}$ before the electric shock or at $5 \mathrm{~min}$ before the first acquisition trial with the RAWM. We found no beneficial effect both on the freezing time and the number of errors in sildenafil-injected APP/PS1 mice (sildenafil-treated APP/PS1 mice demonstrated a freezing time equal to $\sim 90 \%$ that of vehicle-treated APP/PS1 mice; $n=7$ males for sildenafil-treated transgenics and 6 males for vehicle-treated transgenics, $p>0.05 ; \sim 5$ errors in the retention trial for both sildenafil- and vehicle-treated transgenics; $n=6$ males for sildenafil-treated transgenics and 5 males for vehicle-treated transgenics, $p>0.05$; sildenafil did not affect the behavioral performance of WT mice in both tasks; $n=5$ males for all the conditions; data not shown). Thus, all the behavioral experiments on the short-term effects of sildenafil reported in the Results section were performed with injection after the training. Finally, in a separate set of experiments, we tested the effect of intraperitoneal injection of tadalafil on memory.

\section{Sildenafil pharmacokinetic}

To determine the time course of sildenafil action in the brain, we investigated the pharmacokinetic and blood-brain barrier (BBB) penetration capability of the inhibitor. In these experiments, sildenafil was administered to mice at a dosage of $50 \mathrm{mg} / \mathrm{kg}$. Blood and brain samples were collected at six time points $(0,0.25,0.5,1.0,2.0$, and $4.0 \mathrm{~h})$ from three animals per time point. For plasma measurements, blood $(\sim 250 \mu \mathrm{l})$ was collected via retro-orbital puncture into tubes containing sodium heparin. Plasma was separated via centrifugation $\left(4^{\circ} \mathrm{C}, 3500 \mathrm{rpm}, 10 \mathrm{~min}\right)$ and stored at $-80^{\circ} \mathrm{C}$. At the time of measurement, frozen plasma samples were thawed at room temperature and vortexed. Plasma $(25 \mu \mathrm{l})$ was transferred into a $1.5 \mathrm{ml}$ Eppendorf tube. To each sample, $25 \mu \mathrm{l}$ of methanol and $25 \mu \mathrm{l}$ of the internal standard were added, followed by the addition of $100 \mu \mathrm{l}$ of methanol. The sample mixture was vortexed for $\sim 1$ min. After centrifugation at $11,000 \mathrm{~g}$ for $5 \mathrm{~min}$, the upper organic layer was transferred to a glass tube and evaporated at $40^{\circ} \mathrm{C}$ under a gentle stream of nitrogen. Residues were dissolved in $150 \mu$ l of the mobile phase and mixed using a Vortex mixer. A $20 \mu \mathrm{l}$ aliquot of the resulting solution was injected onto the liquid chromatography/tandem mass spectrometry (LC/MS/MS) system for analysis. For measurement of brain concentrations, mice were killed by cervical dislocation after blood harvest. Brains were immediately excised, weighed, and rinsed by cold saline and then frozen at $-80^{\circ} \mathrm{C}$ until further processing for LC/MS/MS analysis. On the day of the assay, frozen tissue samples were thawed at room temperature. When completely thawed, each tissue sample of $200 \mathrm{mg}$ was weighed and placed into a plastic tube. Methanol $(1.0 \mathrm{ml})$ was added to facilitate homogenization, which was conducted using a Fluko F6/10 superfine homogenizer for $\sim 1 \mathrm{~min}$. Then, the homogenized samples were vortexed for $1 \mathrm{~min}$. A $25 \mu \mathrm{l}$ aliquot of the homogenized samples was transferred into an Eppendorf tube. To each sample, $25 \mu \mathrm{l}$ of methanol and 25 $\mu l$ of the internal standard were added. The sample mixture was centrifuged at $11,000 \mathrm{~g}$ for $5 \mathrm{~min}$. A $20 \mu \mathrm{l}$ aliquot of the supernatants was diluted to $80 \mu \mathrm{l}$ or $60 \mu \mathrm{l}$ with the mobile phase, and a $10 \mu \mathrm{l}$ aliquot was injected onto the LC/MS/MS system for analysis. Quantification of the drug concentration in each aliquot was achieved by using an internal standard curve of the peak area versus drug concentration. We found that the concentration of the inhibitor reached $\sim 75 \%$ of the max brain concentration after $15 \mathrm{~min}$, whereas the peak was reached at $30 \mathrm{~min}$ (supplemental Fig. 1, available at www.jneurosci.org as supplemental material). Finally, by $4 \mathrm{~h}$, most of the drug was eliminated from both plasma and brain. These data are consistent with similar studies assessing pharmacokinetics and metabolism of sildenafil in mouse (Walker et al., 1999).

\section{Electrophysiological analysis}

Animals were killed by cervical dislocation followed by decapitation. Hippocampi were quickly removed. Transverse hippocampal slices (400 $\mu \mathrm{m}$ ) were cut and recorded according to standard procedures (supplemental material and methods, available at www.jneurosci.org) (Vitolo et al., 2002).

\section{Behavioral studies}

Fear conditioning. This type of cognitive test is much faster than other behavioral tasks that require multiple days of training and testing (Gong et al., 2004). Our conditioning chamber was in a sound-attenuating box. A clear Plexiglas window allowed the experimenter to film the mouse performance with a camera placed on a tripod and connected to the Freezeframe software (MED Associates). To provide background white noise (72 dB), a single computer fan was installed in one of the sides of the sound-attenuating chamber. The conditioning chamber had a 36-bar insulated shock grid floor. The floor was removable, and after each experimental subject, we cleaned it with $75 \%$ ethanol and then with water. Mice were handled once a day for $3 \mathrm{~d}$ before behavioral experiments. Only one animal at a time was present in the experimentation room. For the cued and contextual conditioning experiments, mice were placed in the conditioning chamber for $2 \mathrm{~min}$ before the onset of a discrete tone [conditioned stimulus (CS)] (a sound that lasted $30 \mathrm{~s}$ at $2800 \mathrm{~Hz}$ and 85 $\mathrm{dB}$ ). In the last $2 \mathrm{~s}$ of the $\mathrm{CS}$, mice were given a foot shock [unconditioned stimulus (US)] of $0.50 \mathrm{~mA}$ for $2 \mathrm{~s}$ through the bars of the floor, except in an experimental series in which we used $0.75 \mathrm{~mA}$ to elicit more memory. After the CS/US pairing, the mice were left in the conditioning chamber for another $30 \mathrm{~s}$ and were then placed back in their home cages. Freezing behavior, defined as the absence of all movement except for that necessitated by breathing, was scored using the Freezeview software. To evaluate contextual fear learning, freezing was measured for $5 \mathrm{~min}$ (consecutive) in the chamber in which the mice was trained $24 \mathrm{~h}$ after training. To evaluate cued fear learning, after contextual testing, the mice were 
placed in a novel context (triangular cage with smooth flat floor and with vanilla odorant) for $2 \mathrm{~min}$ (pre-CS test), after which they were exposed to the CS for $3 \mathrm{~min}$ (CS test), and freezing was measured. Sensory perception of the shock was determined through threshold assessment. A sequence of single foot shocks was delivered to animals placed on the same electrified grid used for fear conditioning. Initially, a $0.1 \mathrm{mV}$ shock was delivered for $1 \mathrm{~s}$, and the animal behavior was evaluated for flinching, jumping, and vocalization. At $30 \mathrm{~s}$ intervals, the shock intensity was increased by $0.1 \mathrm{mV}$ to $0.7 \mathrm{mV}$ and then returned to $0 \mathrm{mV}$ in $0.1 \mathrm{mV}$ increments at $30 \mathrm{~s}$ intervals. Threshold to vocalization, flinching, and then jumping was quantified for each animal by averaging the shock intensity at which each animal manifests a behavioral response to the foot shock. No difference was observed among different groups of mice in the experiments in which fear conditioning was tested in the presence of sildenafil or vehicle.

Spatial working memory. The task studied with the RAWM test has been described previously (Trinchese et al., 2004). Briefly, the RAWM consisted of a white tank filled with water $\left(24-25^{\circ} \mathrm{C}\right)$ and made opaque by the addition of nontoxic white paint. Within the tank walls were positioned so as to produce six arms, radiating from a central area. Spatial cues were presented on the walls of the testing room. At the end of one of the arms was positioned a clear $10 \mathrm{~cm}$ submerged platform that remained in the same location for every trial in $1 \mathrm{~d}$ but was moved approximately randomly from day to day. On each trial, the mouse started the task from a different randomly chosen arm. The mouse did not use its long-term memory of the location of the platform on previous days but relied on the short-term memory of its location on the day in question based on spatial cues that were present in the room. Each trial lasted $1 \mathrm{~min}$, and errors were counted each time the mouse entered the wrong arm or needed $>20$ $s$ to reach the platform. After each error, the mouse was pulled back to the start arm for that trial. After four consecutive acquisition trials, the mouse was placed in its home cage for $30 \mathrm{~min}$, then returned to the maze and administered a fifth retention trial. Testing was considered completed as the WT mice made the same number of errors at the fourth and fifth trial. The scores for each mouse on the last $3 \mathrm{~d}$ of testing were averaged and used for statistical analysis.

Reference memory. The task studied with the Morris water maze has been described previously (Trinchese et al., 2004). Briefly, mice were trained in two daily sessions ( $4 \mathrm{~h}$ apart), each consisting of three trials (1 min each), for $3 \mathrm{~d}$, so that mice had to rely on long-term memory of platform location of previous days. Time required to reach the hidden platform was recorded. To test the retention of the spatial memory, four probe trials were performed after the training with the platform moved. The maze was divided into four quadrants. The percentage of time spent in the quadrant that previously contained the platform was recorded and analyzed with a video tracking system (HVS 2020; HVS Image).

Visible platform testing. Visible platform training to test visual and motor deficits was performed in the same pool as in the Morris water maze, with the platform marked with a black flag and positioned randomly from trial to trial. Time to reach the platform and speed was recorded and analyzed with a video tracking system (HVS 2020; HVS Image).

\section{Immunocytochemical experiments}

Immunocytochemical measurements of phosho-CREB were performed as described previously (supplemental material and methods, available at www.jneurosci.org) (Puzzo et al., 2005).

\section{Determination of $A \beta$ levels}

Frozen hemibrains were weighed and homogenized in $5 \mathrm{~m}$ guanidine $\mathrm{HCl} / 50 \mathrm{~mm}$ Tris $\mathrm{HCl}$ solution. $\mathrm{A} \beta_{40}$ and $\mathrm{A} \beta_{42}$ were measured using human $\beta$-amyloid ELISA kits (Biosource, according to the manufacturer's protocol. ELISA signals were reported as the mean \pm SEM in nanograms of $\mathrm{A} \beta$ per milligram of cortex.

\section{Statistical analyses}

For all experiments, mice were coded to "blind" investigators with respect to genotype and treatment. Data were expressed as mean \pm SEM. Results were analyzed with Student's $t$ test (pairwise comparisons) or ANOVA with post hoc correction (multiple comparisons). The level of significance was set for $p<0.05$. Nonlinear regression analysis was used to fit curves for different concentrations using Systat software.

\section{Results}

\section{Acute effects of sildenafil on synaptic function in} hippocampal slices of APP/PS1 mice

Our first goal was to determine whether PDE5 inhibition can ameliorate synaptic function. Because sildenafil is reported to clearly cross the BBB (FDA, 1998), whereas evidence for vardenafil is indirect (Prickaerts et al., 2004), and tadalafil does not cross it, we chose this compound as a primary drug inhibiting PDE5 for our CNS studies. Sildenafil has an $\mathrm{IC}_{50}$ against PDE5 of $6.0 \mathrm{nM}$ and an in vivo half-life of $0.4 \mathrm{~h}$ in rodents $(\sim 4 \mathrm{~h}$ in humans) (Walker et al., 1999; Daugan et al., 2003b). We first tested whether a brief application of sildenafil was capable of rescuing the defect of LTP in slices derived from 3-month-old APP/PS1 mice, when synaptic plasticity impairment is just starting, whereas basal synaptic transmission (BST) is normal (Trinchese et al., 2004). BST was determined by plotting the peak amplitude of the fiber volley against the slope of the field EPSPs (fEPSPs) and also the fEPSP slope at increasing stimulus intensity in APP/ PS1 and WT mice. We did not find a difference in BST among different groups (Fig. 1A; supplemental Fig. 2 and supplemental discussion, available at www.jneurosci.org as supplemental material). Hippocampal slices were then perfused with sildenafil (50 $\mathrm{nM}$ ) for 10 min before inducing LTP through tetanic stimulation of the Schaeffer collateral pathway. Potentiation in sildenafil treated APP/PS1 slices was far greater than in vehicle-treated APP/PS1 slices (Fig. $1 B$ ). However, sildenafil did not change the amplitude of LTP in slices of WT mice compared with WT slices treated with vehicle alone (Fig. 1C). Sildenafil had no effect on basal synaptic responses either during its application or $120 \mathrm{~min}$ after the end of the application in experiments where no tetanus was applied either in slices from APP/PS1 mice or WT littermates (Fig. $1 B, C$ ). Use of different concentrations of sildenafil showed that $50 \mathrm{~nm}$ was the minimum dose of the drug that completely rescued synaptic plasticity in slices from transgenic animals, whereas lower concentrations were less effective (Fig. $1 D$ ). The same concentrations of the inhibitor did not have an effect on LTP of WT slices (data not shown). In additional experiments, we also found that $50 \mathrm{nM}$ sildenafil was capable of ameliorating LTP in slices from APP/PS1 mice that were potentiated through 1 or 2 series of theta-burst stimulations (Fig. $1 E$ ). Interestingly, as previously shown on slices from WT mice that received a weaker tetanic stimulation paired with agonists of the NO pathway (Puzzo et al., 2005), $50 \mathrm{~nm}$ sildenafil increased the LTP amplitude in WT slices that received one theta-burst stimulation (Fig. 1E).

As a control for PDE5 specificity of the sildenafil effect onto synaptic dysfunction, we next used a more specific PDE5 inhibitor, tadalafil. Differently than sildenafil and vardenafil which are cGMP-based inhibitors, tadalafil is a $\beta$-carbolines-derived drug with no effect on PDE1 (selectivity ratio >2000) and on PDE6 (selectivity ratio 1000) and an $\mathrm{IC}_{50}$ against PDE5 of $5.0 \mathrm{~nm}$ (Daugan et al., 2003b). When slices were bathed in tadalafil (50 nM, 10 min before tetanus), potentiation in APP/PS1 slices was far greater than in vehicle-treated APP/PS1 slices (supplemental Fig. $3 A$, available at www.jneurosci.org as supplemental material). Tadalafil did not affect baseline and LTP in WT mice (supplemental Fig. 3B, available at www.jneurosci.org as supplemental material).

As an additional control for PDE5 specificity, we also used a highly selective PDE1 inhibitor called IC354, the $\mathrm{HCl}$ salt of IC224 [ $\mathrm{IC}_{50}$ against PDE1 of $80 \mathrm{~nm}$; ratio of $\mathrm{IC}_{50}$ value for the next 
most sensitive PDE to $\mathrm{IC}_{50}$ value for PDE1 equal to 127 (Snyder et al., 2005)]. Differently than sildenafil or tadalafil, when APP/PS1 slices were bathed in IC354 (1 $\mu \mathrm{M}, 10 \mathrm{~min}$ before tetanus), LTP was not affected (supplemental Fig. 3C, available at www.

jneurosci.org as supplemental material). IC354 did not change LTP amplitude in hippocampal slices of WT mice (supplemental Fig. 3D, available at www.jneurosci. org as supplemental material). Thus, these results together with the experiments with sildenafil and tadalafil demonstrate that inhibition of PDE5 (but not PDE1) protects AD-like animal models against synaptic dysfunction, supporting that inhibition of PDE5 might be beneficial against synaptic dysfunction in $\mathrm{AD}$.

\section{Acute effects of sildenafil on the cognitive function of APP/PS1 mice} As reported above, sildenafil offers the advantage of crossing the $\mathrm{BBB}$, and, therefore, it can be easily used in behavioral experiments. We divided 3-month-old mice into four groups: APP/PS1 with sildenafil, APP/PS1 with vehicle, WT with sildenafil, and WT with vehicle. Sildenafil and vehicle control solutions were administered intraperitoneally at a concentration of 3 $\mathrm{mg} / \mathrm{kg}$. This concentration was chosen based on previous studies showing that these amounts of sildenafil raise hippocampal cGMP levels and improve memory in aged rats (Prickaerts et al., 2002a) and mice (Baratti and Boccia, 1999) independent of vascular effects (Prickaerts et al., 2002a). We first examined the effects of acute administration of sildenafil on fear-conditioning learning, a type of learning that is impaired in several AD mouse models (Gong et al., 2004) and depends on hippocampus and amygdala (Phillips and LeDoux, 1992). For contextual fear conditioning, mice were trained to associate neutral stimuli with an aversive one. They were placed in a novel context (fear conditioning box), exposed to a white noise cue (CS) paired with a mild foot shock (US), and injected with sildenafil immediately after the training. Fear learning was assessed $24 \mathrm{~h}$ later by measuring freezing behavior-the absence of all movement except for that necessitated by breathing - in response to representation of the context or of the auditory cue within a completely different context. We found no difference in the freezing behavior among the four groups of mice before the training phase (Fig. 2A). Twenty-four hours later, we found a decrease in the freezing behavior of vehicle-treated APP/
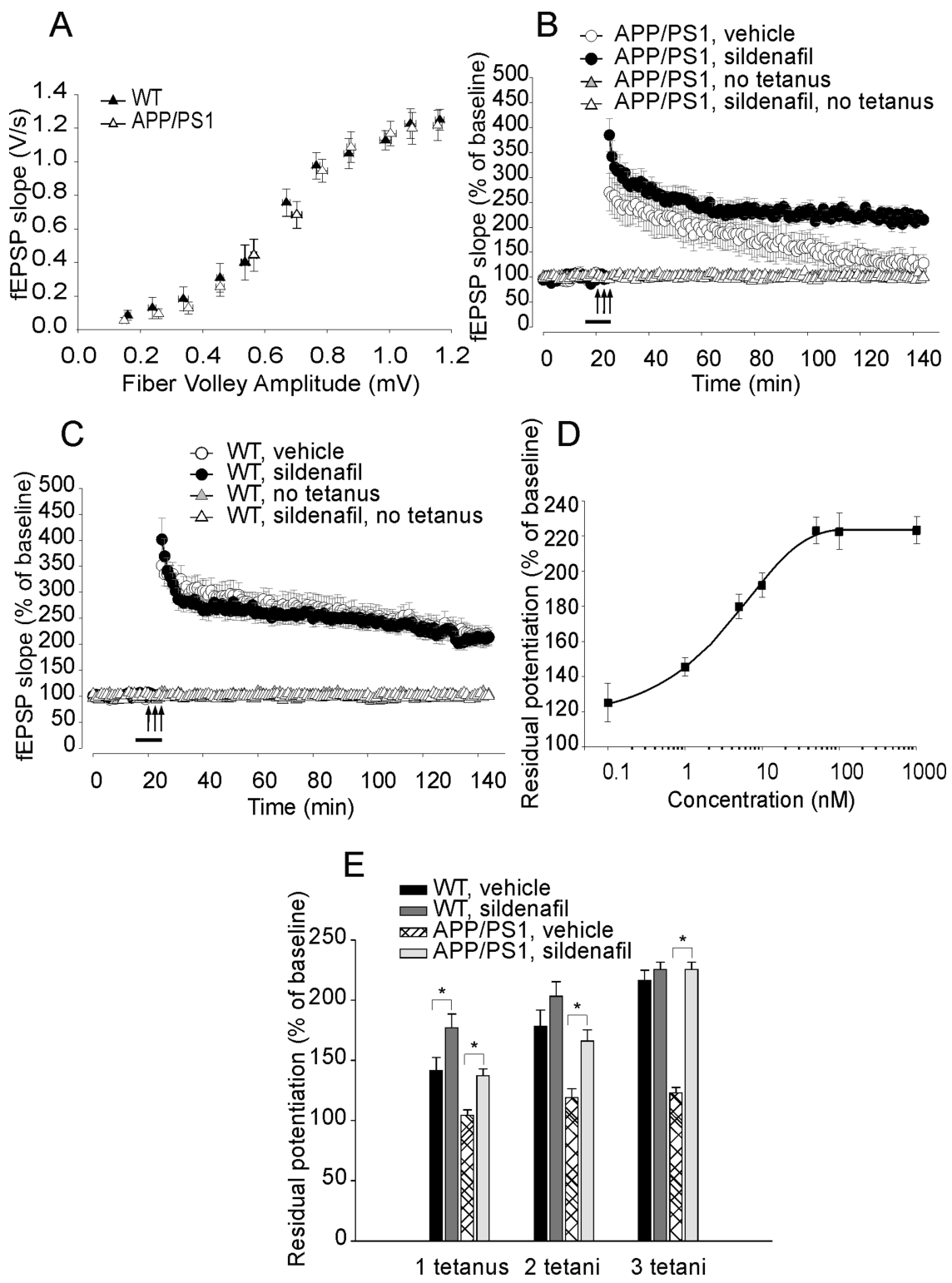

Figure 1. A brief perfusion of hippocampal slices with sildenafil reverses CA1-LTP impairment in 3-month-old APP/PS1 mice. A, BST is similar in 3-month-old APP/PS1 animals and WT littermates. Summary graph of EPSP slopes versus fiber volley amplitudes for different stimulation intensities ranging from 5 to $35 \mathrm{~V}$ ( $35 \mathrm{~V}$ : $\sim 97 \%$ of WT littermates in APP/PS1 mice, $n=7$ slices from 6 males vs $n=7$ slices from 6 males in WT slices; two-way ANOVA; $F_{(1,12)}=0.05, p=0.81$ ). There is no difference in fiber volley between WT and transgenic animals $\left(F_{(1,12)}=3.97, p=0.06\right)$. $\boldsymbol{B}$, Ten minute perfusion with sildenafil $(50 \mathrm{~nm})$ reverses LTP impairment in APP/PS1 mice (sildenafiltreated APP/PS1 mice equal to $\sim 100 \%$ of vehicle-treated WT littermates at 120 min after tetanus, vs $\sim 65 \%$ in vehicle-treated APP/PS1 mice; sildenafil-treated APP/PS1 mice: $n=8$ slices from 7 males; vehicle-treated APP/PS1 mice: $n=9$ slices from 7 males; $F_{(1,15)}=4.98$, $p=0.041$ ). The inhibitor has no effect on basal neurotransmission either during its application or $120 \mathrm{~min}$ after the end of the application in experiments where no tetanic stimulation is applied ( $~ 96 \%$ of vehicle-treated WT slices in sildenafil-treated APP/PS1 slices, vs $\sim 97 \%$ in vehicle-treated transgenic slices; $A$ PP/PS1: $n=4$ slices from 4 males, vehicle-treated WT slices, $n=5$ slices from 4 males; $F_{(1,7)}=1.15$, $p=0.31$ ). Arrows indicate time and pattern of the tetani in this and the following figures. Bars represent the time of the application of the drug or vehicle in this and the following figures. C, Sildenafil ( $50 \mathrm{~nm}$ ) does not affect LTP in WT mice. Levels of LTP at 120 min after tetanus were $\sim 99 \%$ of vehicle-treated WT slices (vehicle-treated WT mice: $n=10$ slices from 8 males, sildenafil-treated WT mice: $n=9$ slices from 8 males; $\left.F_{(1,17)}=0.23, p=0.63\right)$. The inhibitor has no effect on basal synaptic responses either during its application or 120 min after the end of the application in experiments where no tetanic stimulation is applied ( $\sim 97 \%$ of vehicle-treated WT slices; sildenafil-treated slices: $n=5$ slices from 4 males; vehicle-treated slices: $n=4$ slices from 4 males; $\left.F_{(1,7)}=0.26, p=0.62\right)$. These experiments were interleaved with those of APP/PS1 mice. $\boldsymbol{D}$, A dose-response curve shows the effect of different concentrations of sildenafil on synaptic plasticity in slices from transgenic animals. The minimum effective dose that completely rescues synaptic plasticity is $50 \mathrm{~nm}$ ( $n=6$ slices from 6 males for each group). E, Sildenafil ( $50 \mathrm{~nm}$ ) was also capable of ameliorating LTP in slices from APP/PS1 mice that were potentiated through 1 or 2 series of theta-burst stimulations ( 1 tetanus: $t_{(1,10)}=3.38, p=0.007$ compared with vehicle-treated APP/PS1 slices; 2 tetani: $t_{(1,10)}=3.92, p=0.003 ; 3$ tetani: $t_{(1,10)}=13.47, p<0.001 ; n=6$ slices from 6 males for each group). Slices from WT mice that received one theta-burst stimulation showed a significant increase in LTP when they were perfused with $50 \mathrm{~nm}$ sildenafil compared with vehicle-treated WT slices ( 1 tetanus: $t_{(1,10)}=2.25, p=0.048 ; 2$ tetani: $t_{(1,10)}=1.37, p=0.200 ; 3$ tetani: $t_{(1,10)}=1.26, p=0.236 ; n=$ 6 slices from 6 males for each group). Asterisks denote a significant difference in this and all the remaining graphs. 

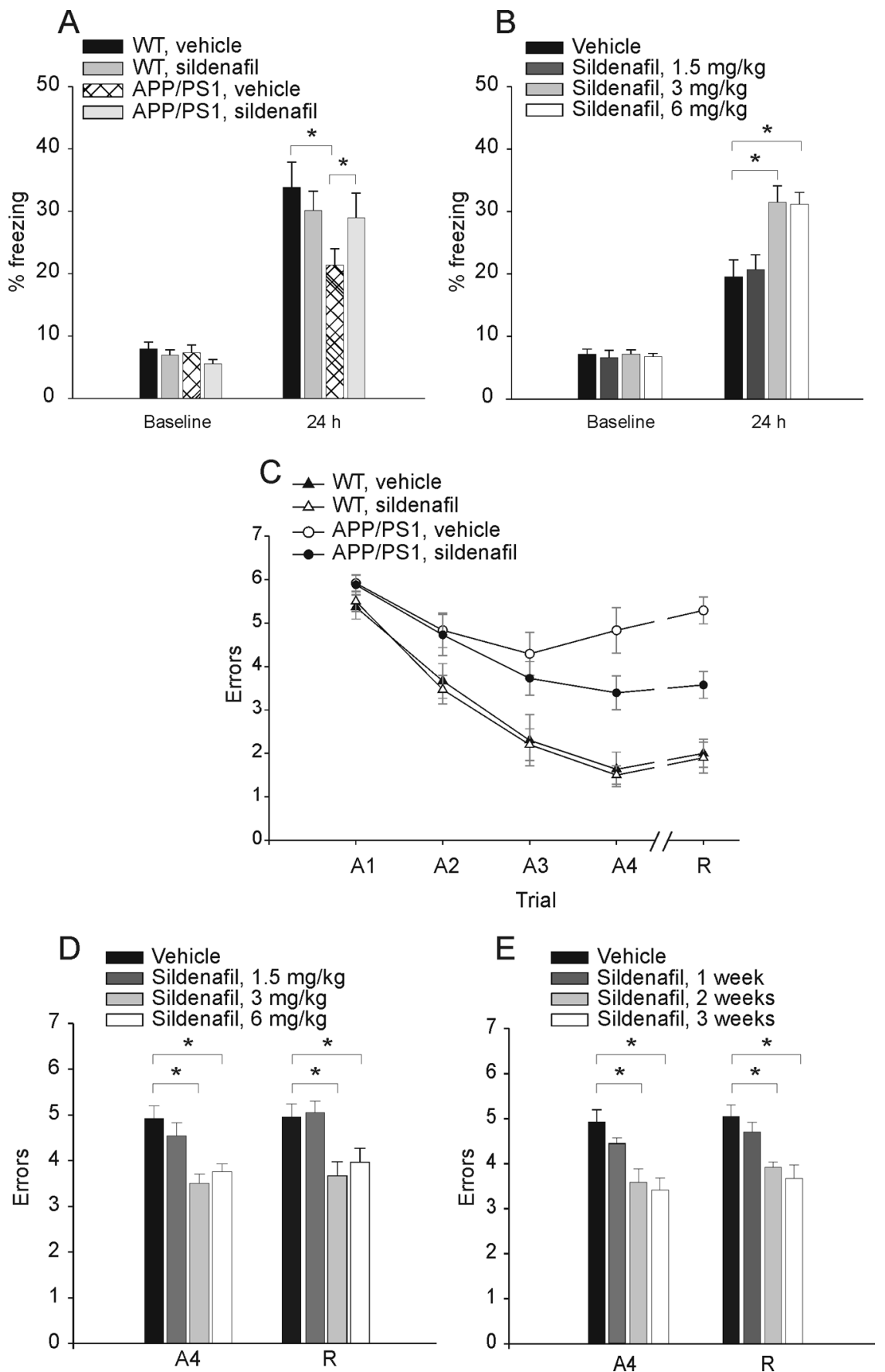

Figure 2. Sildenafil ameliorates cognitive function in 3-month-old APP/PS1 mice. A, Sildenafil (3 mg/kg, i.p.) improves contextual fear conditioning in 3-month-old APP/PS1 mice. APP/PS1 and WT littermates treated with sildenafil or vehicle show no difference in freezing before training (baseline; one-way ANOVA among the 4 groups: $F_{(3,79)}=2.39, p=0.07$ ), whereas contextual fear conditioning performed $24 \mathrm{~h}$ after training shows a reduction of freezing responses in APP/PS1 mice treated with vehicle compared with vehicle-treated WT littermates [the freezing time of vehicle-treated APP/PS1 mice was $\sim 63 \%$ of vehicletreated WT mice; $n=21$ (12 males and 9 females), WT littermates, $n=20$ (11 males and 9 females), $F_{(1,39)}=6.64, p=0.01$ ]. The freezing response is improved in sildenafil-treated APP/PS1 mice [the freezing time of sildenafil-treated APP/PS1 mice was $\sim 87 \%$ of vehicle-treated WT mice: $n=22$ (12 males and 10 females); $F_{(1,40)}=0.73, p=0.39$ ]. Sildenafil has no effect on the freezing responses of WT mice compared with vehicle-treated WT littermates [ $\sim 89 \%$ of vehicle-treated WT mice: $n=20$ (11 males and 9 females); $\left.F_{(1,38)}=0.52, p=0.47\right]$. $\boldsymbol{B}$, The minimum concentration of sildenafil needed to improve contextual fear memory in APP/PS1 mice is $3 \mathrm{mg} / \mathrm{kg}$. A concentration of $1.5 \mathrm{mg} / \mathrm{kg}$ does not improve freezing, whereas $6 \mathrm{mg} / \mathrm{kg}$ has the same effect as $3 \mathrm{mg} / \mathrm{kg}\left[1.5 \mathrm{mg} / \mathrm{kg}\right.$ sildenafil: $n=8$ ( 4 males, 4 females) vs vehicle-treated animals, $n=14$ ( 7 males, 7 females), $F_{(1,20)}$ $=0.82, p=0.375 ; 3 \mathrm{mg} / \mathrm{kg}$ sildenafil: $n=8$ (4 males, 4 females), $F_{(1,20)}=11.58, p=0.003 ; 6 \mathrm{mg} / \mathrm{kg}$ sildenafil: $n=8$ (4 males, 4 females), $\left.F_{(1,20)}=8.48, p=0.009\right]$. C, Sildenafil (3 mg/kg, i.p.) improves spatial working memory in 3-month-old APP/PS1 mice. APP/PS1 mice treated with vehicle do not learn the position of the hidden platform compared with vehicle-treated WT littermates [APP/PS1: $n=8$ (4 males and females); WT: $n=10$ (5 males and females); two-way ANOVA: $\left(F_{(1,16)}=39.66, p<\right.$ 0.0001 , and planned comparisons show that the two groups are significantly different at the second acquisition trial (A2) ( $p=$
PS1 mice compared with that of vehicletreated WT littermates in the analysis of the contextual learning (Fig. 2A). Sildenafil treatment improved contextual learning in the transgenic animals (Fig. $2 A$ ), whereas sildenafil-treated WT animals did not show a significant increase in freezing (Fig. $2 \mathrm{~A}$ ), probably because maximal levels of memory are already induced in vehicle-treated WT mice after the training session, as has been found both in Drosophila and in mice (Tully et al., 2003; Gong et al., 2004). We next tested cued fear conditioning, a hippocampus-independent task (Phillips and LeDoux, 1992), and did not find a difference in freezing among the four groups (supplemental Fig. 4, available at www.jneurosci.org as supplemental material), as APP/PS1 mice are known to have a selective hippocampus-dependent impairment in associative learning (Gong et al., 2004). Moreover, as for the electrophysiological experiments, we determined the minimum concentration of sildenafil needed to improve contextual fear memory in APP/PS1 mice by injecting $1.5 \mathrm{mg} /$ $\mathrm{kg}, 3 \mathrm{mg} / \mathrm{kg}$, and $6 \mathrm{mg} / \mathrm{kg}$ inhibitor. We found that a concentration of $3 \mathrm{mg} / \mathrm{kg}$ fully restored fear memory (Fig. $2 B$ ). No memory enhancement was observed in WT littermates injected with the different concentrations of inhibitor (data not shown).

Next, we examined the effect of treat-

$0.05), \mathrm{A} 3(p=0.02), \mathrm{A} 4$, and recall trial $(\mathrm{R})(p<0.0001)]$ However, treatment with sildenafil ameliorates the performance of double transgenic littermates compared with vehicle-treated APP/PS1 $[n=11$ ( 6 males and 5 females); $F_{(1,17)}=5.99, p=0.02$, and planned comparisons show that the 2 groups are significantly different at trial A4 ( $p=0.03$ ) and $R(p=0.001)$ ]. Sildenafil does not affect the performance of WT mice compared with vehicle-treated WT mice [sildenafil: $n=10$ ( 5 males and females); $F_{(1,18)}=0.09, p=$ $0.76]$. $\boldsymbol{D}$, The minimum concentration of sildenafil needed to improve spatial working memory in APP/PS1 mice is $3 \mathrm{mg} / \mathrm{kg}$ for 3 weeks. A concentration of $1.5 \mathrm{mg} / \mathrm{kg}$ does not improve RAWM performance, whereas $6 \mathrm{mg} / \mathrm{kg}$ has the same effect as $3 \mathrm{mg} / \mathrm{kg}$ [1.5 mg/kg sildenafil: $n=8$ (4 males, 4 females) vs vehicle-treated animals: $n=14$ ( 7 males, 7 females), $F_{(1,20)}$ $=0.82, p=0.375$ and $F_{(1,20)}=0.05, p=0.824$ for $A 4$ and $\mathrm{R}$, respectively; $3 \mathrm{mg} / \mathrm{kg}$ sildenafil: $n=8$ ( 4 males, 4 females), $F_{(1,20)}=11.58, p=0.003$ and $F_{(1,20)}=11.36, p=0.003 ; 6$ $\mathrm{mg} / \mathrm{kg}$ sildenafil: $n=8$ ( 4 males, 4 females), $F_{(1,20)}=8.48$, $p=0.009$ and $\left.F_{(1,20)}=7.12, p=0.015\right]$. E, Summary graph showing that the minimum time needed for sildenafil to have a positive effect on spatial working memory in APP/PS1 mice is 2 weeks, with a concentration of $3 \mathrm{mg} / \mathrm{kg}\left[1\right.$ week: $F_{(1,20)}=$ $1.81, p=0.19$ and $F_{(1,20)}=0.82, p=0.386$ for $A 4$ and $\mathrm{R}$, respectively; 2 weeks: $F_{(1,20)}=9.69, p=0.005$ and $F_{(1,20)}=$ $10.35, p=0.004 ; 3$ weeks: $F_{(1,20)}=13.19, p=0.002$ and $F_{(1,20)}=11.36, p=0.003 ; n=8$ (4 males, 4 females) for each condition]. 
ment with sildenafil on spatial working memory, a type of shortterm memory that can be studied with the RAWM test. This task has already demonstrated memory deficits in other transgenic models of AD (Morgan et al., 2000; Trinchese et al., 2004) and has been shown to depend upon hippocampal function (Diamond et al., 1999). Mice were required to learn and memorize the location of a hidden platform in one of the arms of a maze with respect to spatial cues. APP/PS1 injected with vehicle showed severe abnormalities in spatial memory for platform location during both acquisition and retention of the task compared with vehicleinjected WT littermates (Fig. 2C). However, daily injections of sildenafil for 3 weeks immediately after the fourth acquisition trial ameliorated the behavioral performance of APP/PS1 mice (Fig. 2C). Treatment with sildenafil did not affect the performance of WT mice compared with vehicle-injected WT littermates (Fig. 2C). We also determined the minimum concentration of sildenafil needed to improve spatial working memory in APP/PS1 mice by injecting the drug for 3 weeks with $1.5 \mathrm{mg} / \mathrm{kg}, 3$ $\mathrm{mg} / \mathrm{kg}$, and $6 \mathrm{mg} / \mathrm{kg}$ inhibitor. We found that a concentration of $3 \mathrm{mg} / \mathrm{kg}$ fully restored memory (Fig. $2 \mathrm{D}$ ). Then, we tested the minimum time needed for sildenafil to have a positive effect on spatial working memory. We found that daily injections of 3 $\mathrm{mg} / \mathrm{kg}$ sildenafil improved APP/PS1 mouse performance after 2 weeks (Fig. 2 E). The four groups of mice showed no difference in the time needed to find the platform in the visible platform task, as well as in swimming speed (supplemental Fig. 5, available at www.jneurosci.org as supplemental material). Thus, vision, motor coordination, or motivation were not affected in the four groups of mice and could not influence the RAWM results.

An interesting difference between the results with RAWM and fear conditioning was related to the fact that sildenafil produces a partial rescue with the RAWM experiments in APP/PS1 mice, whereas rescue was complete with contextual fear conditioning. To exclude that this difference was attributable to an incomplete formation of memory in the WT mice facilitating the task of sildenafil to equalize memory between transgenic and WT littermates, we performed an additional series of experiments in which we increased the intensity of the foot shock from 0.50 to $0.75 \mathrm{~mA}$. This procedure is known to increase the amount of freezing. We found that regardless of the amounts of freezing, sildenafil was still capable of fully restoring memory in APP/PS1 mice, unlike the RAWM experiments and like the experiments with lower intensity of the foot shock (supplemental Fig. 6, available at www.jneurosci.org as supplemental material).

To exclude the possibility that sildenafil produced its behavioral effect through a peripheral vascular action, we repeated the memory studies using tadalafil, which is unable to cross the $\mathrm{BBB}$ $(\mathrm{cLogP}=1.43$ and information from its manufacturer). We found that tadalafil ( $1 \mathrm{mg} / \mathrm{kg}$, i.p.) did not improve either contextual fear conditioning or spatial working memory in APP/PS1 mice. Thus, the effect of sildenafil cannot be attributable to inhibition of PDE5 in the vascular compartment (supplemental Fig. 7 and supplemental discussion, available at www.jneurosci.org as supplemental material).

\section{Persistent effects of sildenafil on cognitive and synaptic functions in APP/PS1 mice}

Previous studies have demonstrated that the PDE4 inhibitor rolipram has a prolonged beneficial effect on synaptic and cognitive abnormalities in APP/PS1 mice that persists beyond the administration of the inhibitor (Gong et al., 2004). This finding has opened a very interesting therapeutic perspective when using drugs upregulating CREB phosphorylation in $\mathrm{AD}$ : a brief course of treatment might be beneficial for a long time. To check whether the same effect is present after sildenafil treatment, we examined whether the PDE5 inhibitor maintains its protective effect against synaptic dysfunction and memory loss. In these experiments, both APP/PS1 and WT mice of 3 months of age were injected intraperitoneally with $3 \mathrm{mg} / \mathrm{kg} / \mathrm{d}$ sildenafil for 3 weeks, then the treatment was stopped for 9-12 weeks before testing. The mice were next subjected to training for contextual learning. As in the acute experiments, when the animals were reintroduced into the same context in which they had been trained 9-12 weeks before, the freezing time was greatly increased in APP/PS1 mice that had been previously treated with sildenafil compared with vehicle-treated APP/PS1 littermates (Fig. 3A). Sildenafil did not increase the freezing time in WT littermates compared with WT mice treated with vehicle (Fig. $3 A$ ). There were no differences between the four groups in the cued conditioning test (data not shown). We also found that 3 $\mathrm{mg} / \mathrm{kg}$ was the minimum dose of inhibitor capable of producing the prolonged beneficial effect on contextual fear memory (supplemental Fig. $8 \mathrm{~A}$, available at www.jneurosci.org as supplemental material), and 2 weeks were the minimal effective number of days of sildenafil delivery (supplemental Fig. $8 B$, available at www.jneurosci.org as supplemental material). These data indicate that inhibition of PDE5 is capable of protecting fear contextual learning in APP/PS1 mice for an extended time beyond the duration of drug administration.

The effects of one course of 3 week treatment with sildenafil on spatial working memory were next tested using the RAWM task. As expected (Trinchese et al., 2004), there was a difference between the number of errors made by vehicle-treated APP/PS1 and WT mice (Fig. 3B). Administration of sildenafil for 3 weeks, 9-12 weeks before the testing, reduced the gap between the two groups without affecting performance of the WT animals (Fig. $3 B$ ). In addition, consistent with the experiments with fear conditioning, we found that $3 \mathrm{mg} / \mathrm{kg}$ was the minimum dose of inhibitor capable of producing the prolonged beneficial effect on spatial working memory (supplemental Fig. $8 C$, available at www.jneurosci.org as supplemental material), and 2 weeks were the minimal effective number of days of sildenafil delivery (supplemental Fig. $8 D$, available at www.jneurosci.org as supplemental material). These data indicate that one course of long-term treatment with the PDE5 inhibitor is capable of protecting spatial working memory in APP/PS1 mice.

To investigate sildenafil effect on long-term memory, we tested reference memory with a Morris water maze task that is known to require hippocampal function (Schenk and Morris, $1985)$ and is impaired after 6 months of age in the APP/PS1 mice (Trinchese et al., 2004). Vehicle-treated transgenic mice needed more time to find the hidden platform after six sessions compared with WT littermates (Fig. 3C). When APP/PS1 mice were previously treated with sildenafil, they showed a marked improvement of their behavioral performance. Sildenafil did not affect the performance in WT littermates (Fig. $3 C$ ). We also assessed reference memory with the probe trial, another test of spatial reference memory (Schenk and Morris, 1985). After the sixth hidden-platform session, the platform was removed from the water, and the animals were allowed to search for $60 \mathrm{~s}$. The mouse is thus indicating that it knows the position of the platform independently of such tactile cues as hitting the platform. We found that vehicle-treated WT mice spent more time in the target quadrant (TQ), where the platform had been located during training, than in the other quadrants (Fig. $3 D$ ). We also found 

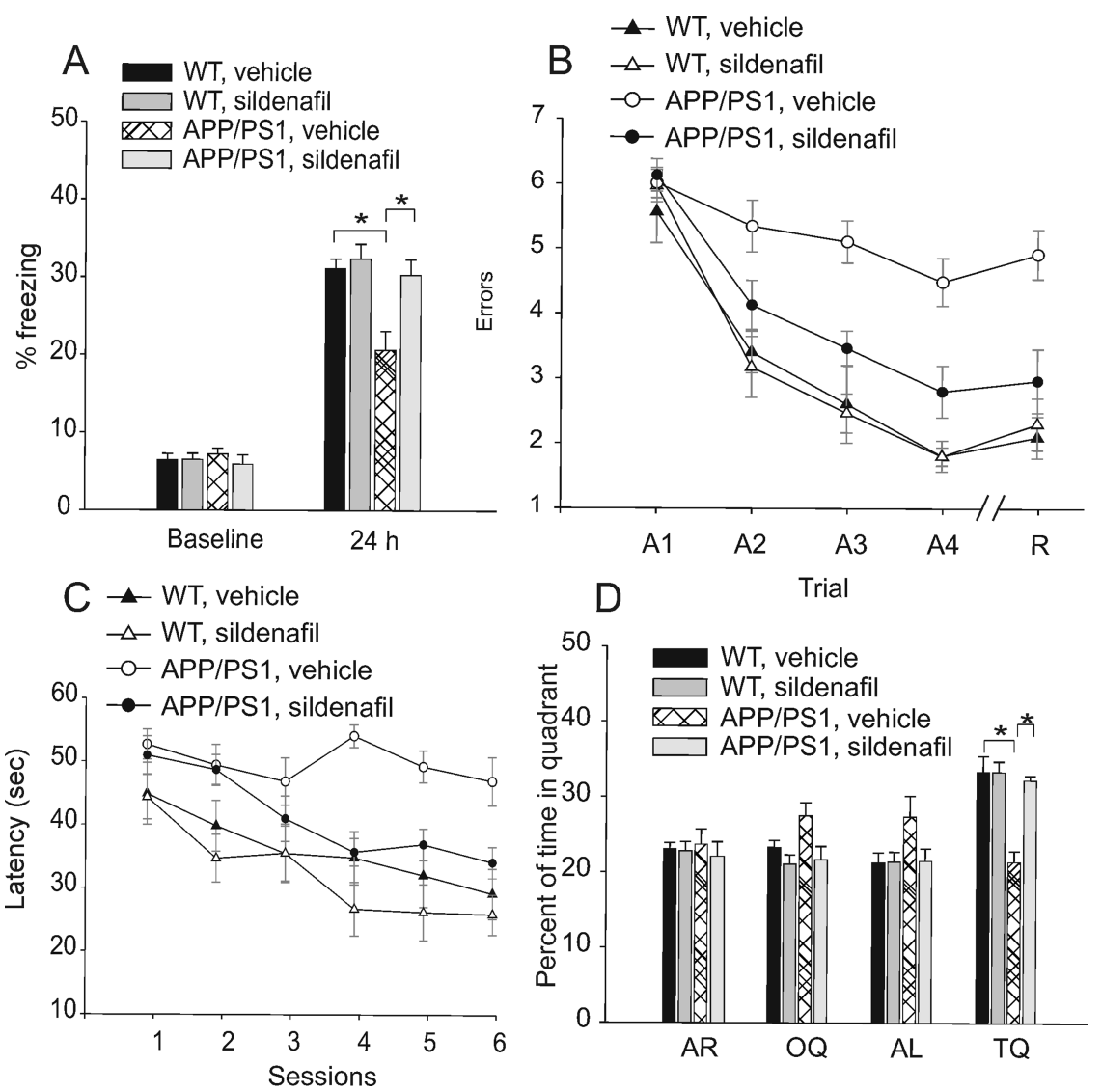

Figure 3. Daily injections of sildenafil ( $3 \mathrm{mg} / \mathrm{kg}$, i.p.; daily for 3 weeks) in 3-month-old APP/PS1 mice improve both associative and spatial memory in 6- to 8-month-old APP/PS1 mice. $A$, Sildenafil ameliorates contextual memory in transgenic mice. After $24 \mathrm{~h}$, the reduction in freezing time of APP/PS1 mice is rescued by sildenafil [ $\sim 97 \%$ of vehicle-treated WT mice in sildenafiltreated APP/PS1 mice, vs $\sim 66 \%$ in vehicle-treated APP/PS1 mice; $n=12$ ( 7 males, 5 females) in sildenafil-treated APP/PS1 mice, $n=17$ (10 males, 7 females) in vehicle-treated APP/PS1 mice, $\left.F_{(1,27)}=7.10, p=0.013\right]$. Sildenafil does not increase freezing in WT littermates $\left[\sim 104 \%\right.$ of vehicle-treated WT mice; $n=17$ ( 10 males, 7 females) vs $n=14$ ( 8 males, 6 females), $F_{(1,29)}$ $=0.28, p=0.06] . B$, Impairment of performance during RAWM in APP/PS1 mice is rescued by sildenafil [APP/PS1: $n=$ 7 (4 males, 3 females); WT: $n=7$ ( 3 males, 4 females); $F_{(1,12)}=31.96, p=0.0001$; planned comparisons show a significant difference after A2 ( $p=0.001)$ ]. Sildenafil improves APP/PS1 mice performance $[n=8$ ( 4 males, 4 females); $F_{(1,13)}=30.40, p=0.0001$ compared with vehicle-treated APP/PS1 mice; planned comparisons show a significant difference after A2 ( $p=0.035)]$ and does not affect WT mice performance $\left[n=7\right.$ ( 4 males, 3 females), $F_{(1,12)}=0.01, p=$ 0.916 compared with vehicle-treated WT animals]. C, APP/PS1 mice performance in the Morris water maze is improved by previous treatment with sildenafil [vehicle-treated transgenic mice: $\sim 155 \%$ of the time needed by the vehicle-treated WT mice; $n=11 / 12, F_{(1,21)}=13.73, p=0.001$; planned comparisons show a significant difference after the fourth session, $p=0.001]$. Previous treatment with sildenafil reduces the time needed to find the platform in APP/PS1 mice compared with vehicle-treated APP/PS1 mice [ $\sim 117 \%$ of the time required by vehicle-treated WT mice; $n=10, F_{(1,19)}=$ $8.81, p=0.008$; planned comparisons for each session reveal a significant difference after the fourth session, $p=$ $0.0001]$. Sildenafil does not affect WT mice performance $[\sim 89 \%$ of the time required by vehicle-treated WT mice; $n=13$, $\left.F_{(1,23)}=0.81 ; p=0.376\right] . \boldsymbol{D}$, In the probe test, sildenafil-treated APP/PS1 mice search significantly more time in the TQ, where the platform was located during training, than vehicle-treated APP/PS1 mice $\left(F_{(1,19)}=12.17, p=0.002\right.$; planned comparisons confirm that they spend significantly more time in the TQ than in the remaining quadrants, $p=0.0001)$. WT mice spend $33.37 \pm 2.10 \%$ of the time in TQ [planned comparisons TQ vs adjacent right quandrant (AR), opposite quadrant (0Q), adjacent left quadrant (AL); $p=0.03, p=0.04, p=0.02$, respectively]. Sildenafil-treated WT mice spend $33.35 \pm 1.38 \%$ of the time in the TQ $\left(F_{(1,423)}=0.001, p=0.998\right.$ compared with vehicle-treated WT mice).

that sildenafil improved the performance of the APP/PS1 mice which searched in the TQ more than the vehicle-treated APP/PS1 mice (Fig. 3D). Sildenafil-treated WT mice remembered where the platform was the previous days and spent approximately the same time as vehicle-treated WT littermates. In addition, consistent with the experiments with fear conditioning and RAWM, we found that $3 \mathrm{mg} / \mathrm{kg}$ was the minimum dose of inhibitor capable of producing the prolonged beneficial effect on reference memory (supplemental Fig. 8E,F, available at www. jneurosci.org as supplemental material), and 2 weeks were the minimal effective number of days of sildenafil delivery (supplemental Fig. $8 G, H$, available at www.jneurosci.org as supplemental material). A visible platform trial performed after the probe trials did not reveal any difference in the time to reach the platform and swimming speed among the four groups (supplemental Fig. 9, available at www.jneurosci.org as supplemental material).

To add depth to the analysis of the functional changes that underlie the striking effects of sildenafil on APP/PS1 mice behavioral performance, we examined synaptic function in hippocampi from the same mice. In contrast to 3-month-old double transgenic mice, 8- to 9-month-old APP/PS1 animals show a reduction of synaptic strength (Trinchese et al., 2004). Previous treatment with sildenafil in APP/PS1 mice produced greater values of fEPSP slope in slices from 8- to 9-month-old mice than in vehicle-treated APP/PS1 slices (Fig. 4A). However, sildenafil did not change responses in WT littermates. CA3-CA1 connections that had been tested for BST were also assessed for their capacity of undergoing potentiation. LTP values recorded from slices obtained from APP/PS1 that had been previously treated with sildenafil were similar to their sildenafil-treated WT littermates and far greater than those from vehicle-treated APP/PS1 littermates (Fig. 4B, C). Eight- to nine-month-old WT mice showed similar amounts of potentiation, whether treated with sildenafil or with vehicle (Fig. 4C). No differences were noted in the baseline transmission of the four groups of mice in the absence of tetanus (Fig. $4 B, C$ ). We also found that $3 \mathrm{mg} / \mathrm{kg}$ was the minimum dose of inhibitor capable of producing the prolonged beneficial effect on BST and LTP (supplemental Fig. $10 A, B$, available at www. jneurosci.org as supplemental material), and 2 weeks were the minimal effective number of days of sildenafil delivery for rescuing these phenomena (supplemental Fig. $10 C, D$, available at www.jneurosci.org as supplemental material). Together, these data indicate that one course of treatment with sildenafil is capable of protecting APP/PS1 mice against synaptic dysfunction for a long time.

In an additional experimental series, we also examined whether treatment of hippocampal slices from 6-month-old APP/PS1 mice with sildenafil produces an immediate improvement of synaptic function. In contrast to BST, which was not ameliorated by the compound, LTP reached normal levels with $500 \mathrm{~nm}$ sildenafil (supplemental Fig. $11 A, B$, available at www.jneurosci.org as supplemental material). Thus, it is likely that once the damage of synaptic function is established, PDE5 inhibition is 

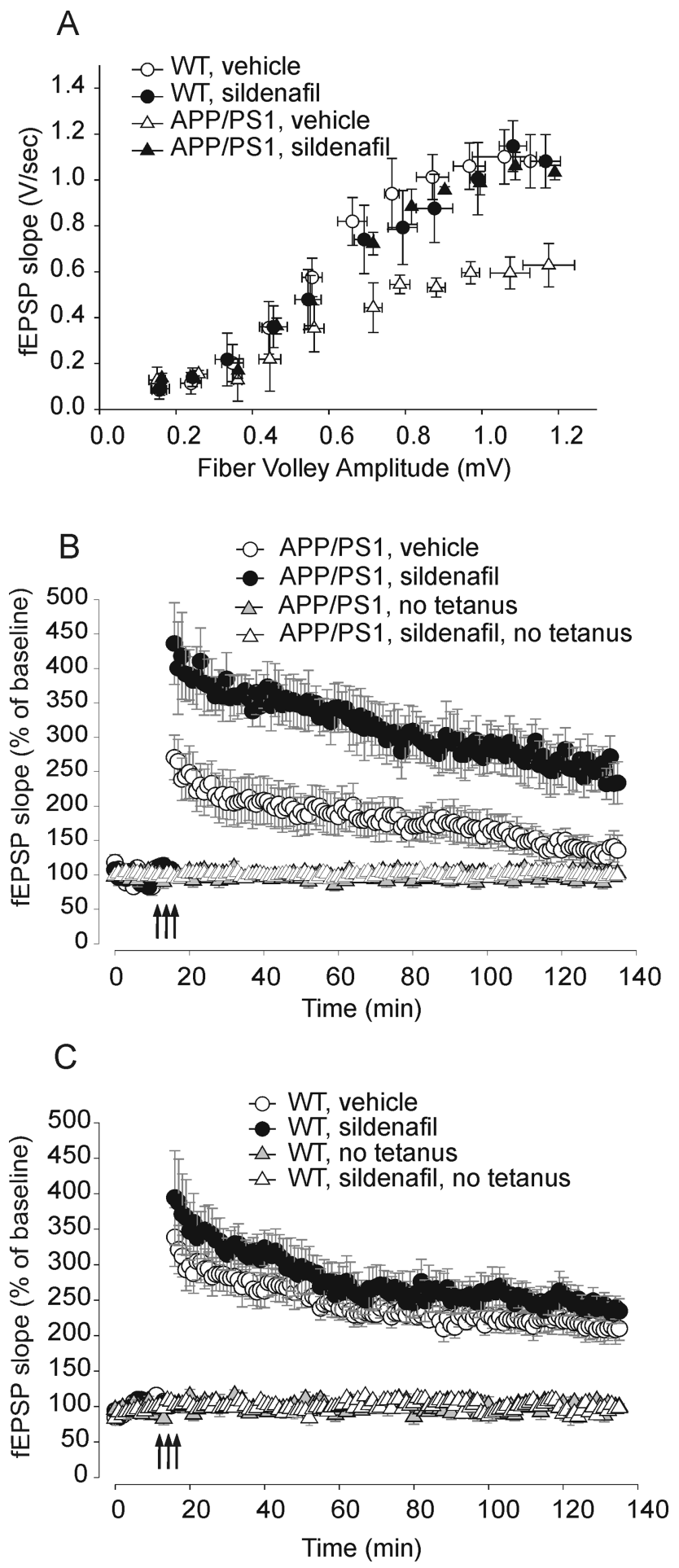

Figure 4. Daily injections of sildenafil (3 mg/kg, i.p.; daily for 3 weeks) in 3-month-old APP/PS1 mice reverse the BST and LTP impairments in hippocampal slices from the same mice at 6-8 months of age. A, BST impairment in APP/PS1 animals is improved by sildenafil treatment (slope of the EPSP at $35 \mathrm{~V}$ : $\sim 57 \%$ of vehicle-treated WT mice in vehicle-treated APP/PS1 mice, $n=6$ slices from 5 males, $F_{(1,9)}=7.26, p=0.02$ compared with vehicle-treated WT mice; sildenafil-treated APP/PS1 mice: $\sim 160 \%$ of vehicle-treated APP/PS1 mice; $n=8$ slices from 6 males, $F_{(1,12)}=5.51, p=0.03$ compared with vehicle-treated transgenic mice). Sildenafil does not change BST in WT mice (sildenafil-treated WT mice: 94\% of vehicle-treated WT mice, $n=6$ from 5 males, vehicle-treated WT mice: $n=5$ slices from 5 males; $F_{(1,9)}=0.34$, $p=0.57)$. Fiber volley is similar in the four groups at $35 \mathrm{~V}\left(F_{(3,21)}=2.26, p=0.11\right) . \boldsymbol{B}$, Sildenafil rescues the LTP impairment in APP/PS1 mice (sildenafil-treated APP/PS1 mice: $\sim 110 \%$ of vehicle-treated WT mice, $n=7$ slices from 6 males, vehicle-treated APP/PS1 mice: $\sim 65 \%$ of vehicle-treated WT mice, $n=7$ slices from 6 males, $\left.F_{(1,12)}=14.82, p=0.002\right)$. C, capable of quickly counteracting defects in synaptic plasticity but not deficits in basal synaptic function.

\section{Effects of sildenafil on CREB phosphorylation and $\mathrm{A} \beta$ levels in APP/PS1 mice}

Given that the duration of action of sildenafil is relatively short, a direct effect of the PDE5 inhibitor cannot be held responsible for its long-term effects. CREB has been implicated in the regulation of genes whose expression results in the formation and stabilization of long-term memory. CREB phosphorylation is required for CREB ability to bind to CREB-binding protein (CBP) and to stimulate CRE-dependent gene expression (Silva et al., 1998). A $\beta$ elevation is also known to block the tetanus-induced increase in phosphorylation of the memory molecule CREB (Puzzo et al., 2005; Gong et al., 2006). Thus, we measured levels of CREB phosphorylation in sildenafil- and vehicle-treated transgenic and WT mice. Hippocampal slices were treated as described in the electrophysiological experiments, fixed 60 min after the treatment, stained with antiphospho-CREB antibodies at Ser-133, and viewed on a confocal microscope. We confirmed previous findings (Lu et al., 1999; Puzzo et al., 2005) showing an increase in immunofluorescence intensity in the CA1 cell body area of WT mice after tetanus compared with control non-tetanized slices (Fig. 5A,B). APP/PS1 animals did not have the physiological increase of CA1 phospho-CREB immunofluorescence after tetanus (Fig. 5A, B). However, sildenafil re-established normal phosphoCREB increase in tetanized slices of the double transgenics (Fig. $5 A, B)$. Sildenafil did not affect the tetanus-induced increase in immunofluorescence in WT animals (Fig. 5A,B).

We obtained similar results when we investigated mice that had been injected with $3 \mathrm{mg} / \mathrm{kg} / \mathrm{d}$ sildenafil or vehicle at the age of 3 months and then left without treatment for 9-12 weeks. Similar to the younger animals, we found an increase in immunofluorescence intensity in CA1 cell body area of WT mice after tetanus compared with non-tetanized control slices (Fig. 5C). APP/PS1 mice did not reveal the physiological increase of phospho-CREB after tetanus, but previous treatment with sildenafil reestablished it (Fig. 5C). Moreover, phospho-CREB immunofluorescence did not vary in slices from sildenafil-treated WT mice with tetanic stimulation (Fig. $5 C$ ). Thus, at the root of the longterm improvement in synaptic physiology and behavior, there is the re-establishment of the increase of CREB phosphorylation in APP/PS1 mice after tetanic stimulation of the Schaffer collateralCA1 connection.

What underlies the long-lasting improvement in CREB phosphorylation in the APP/PS1 mice? To address this question, given that $\mathrm{A} \beta$ downregulates phospho-CREB, we examined whether sildenafil affects $A \beta$ levels. ELISA of extracts of cerebral cortices revealed a reduction in human $\mathrm{A} \beta_{40}$ and $\mathrm{A} \beta_{42}$ levels in sildenafiltreated APP/PS1 mice after 3 week treatment with $3 \mathrm{mg} / \mathrm{kg}$ and 6 $\mathrm{mg} / \mathrm{kg}$ sildenafil at 3 months and 7-10 months (Fig. 6A,B). Treatment with $1.5 \mathrm{mg} / \mathrm{kg}$, in turn, did not decrease $\mathrm{A} \beta$ levels. Finally, when we determined the $\mathrm{A} \beta$ levels in animals treated with $3 \mathrm{mg} / \mathrm{kg}$ sildenafil for different durations, we found that $\mathrm{A} \beta$ levels were already reduced after 2 weeks both in animals that were killed immediately after the treatment (Fig. 6C) and animals that

\footnotetext{
Sildenafil does not affect LTP in WT mice ( $\sim 112 \%$ of vehicle-treated WT mice, $n=7$ slices from 6 males; vehicle-treated WT mice: $n=7$ slices from 6 males, $\left.F_{(1,12)}=2.16, p=0.16\right)$. There are no differences in the baseline transmission of the four groups of mice in the absence of tetanus ( $n=4$ slices from 4 animals for each group, $F_{(3,12)}=0.17, p=0.91$ ).
} 
A
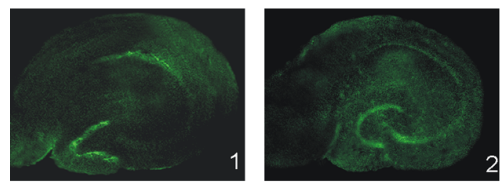

WT, vehicle

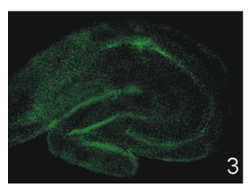

APP/PS1, vehicle
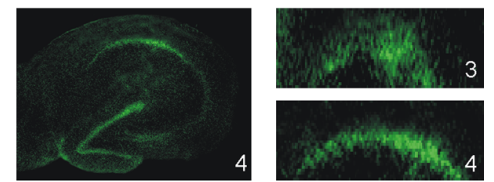

WT, sildenafil APP/PS1, sildenafil

$\mathrm{B}$

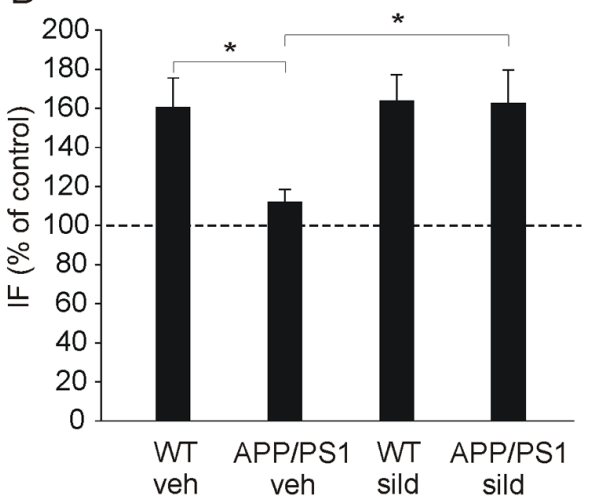

C

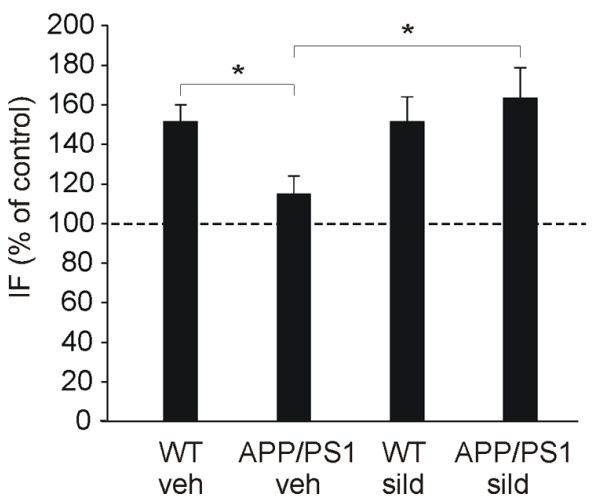

Figure 5. Sildenafil re-establishes normal increase in CREB phosphorylation after tetanic stimulation in APP/PS1 mice. A, Representative examples of hippocampal slices stained with a phosphoCREB antibody. The slices are fixed 60 min after either vehicle (veh) or sildenafil ( $50 \mathrm{~nm}$ ) with tetanus in 3-month-old WT and APP/PS1 animals. Left, Lower-power $(4 \times)$ view of the entire slice. Right, Higher-power $(16 \times)$ view of CA1 cell pyramidal area. $B$, The increase in the intensity of immunofluorescence (IF) in the CA1 cell body area after application of the tetanus does not appearin 3-month-old APP/PS1 mice (WT plus vehicle: $n=4 ; t_{(6)}=3.44, p=0.014$ compared with control non-tetanized WT slices; APP/PS1 plus vehicle: $n=4 ; t_{(6)}=2.96, p=0.025$ compared with tetanized slices from vehicle-treated WT mice). Sildenafil (sild) re-establishes the increase in CREB phosphorylation in APP/ PS1 mice after tetanus, whereas it does not affect phospho-CREB levels in WT tetanized slices (APP) PS1 plus sildenafil: $n=4 ; t_{(6)}=0.044, p=0.966$ compared with tetanized slices of sildenafil-treated WT mice; WT plus sildenafil: $n=4 ; t_{(6)}=0.15, p=0.88$ compared with tetanized slices of vehicletreated WT mice). C, Mice that received daily injections of sildenafil (3 mg/kg, i.p.; for 3 weeks in 3-month-old APP/PS1 mice) show normal tetanus-induced increase in (REB phosphorylation at 6 -8 months of age (WT plus vehicle: $n=4 / 4, t_{(6)}=4.70, p=0.003$ compared with non-tetanized WT slices; APP/PS1 plus vehicle: $n=4, t_{(6)}=2.96, p=0.025$, compared with tetanized slices from vehicle-treated WT littermates; APP/PS1 plus sildenafil: $n=4 ; t_{(6)}=0.609, p=0.565$ compared with tetanized slices of sildenafil-treated WT animals, $t_{(6)}=2.75, p=0.041$ compared with tetanized slices of vehicle-treated APP/PS1 animals). Sildenafil does not affect the increase in CREB phosphorylation in WT mice $\left(n=4, t_{(6)}=0.009, p=0.993\right.$, compared with tetanized slices from vehicle WT mice).
A
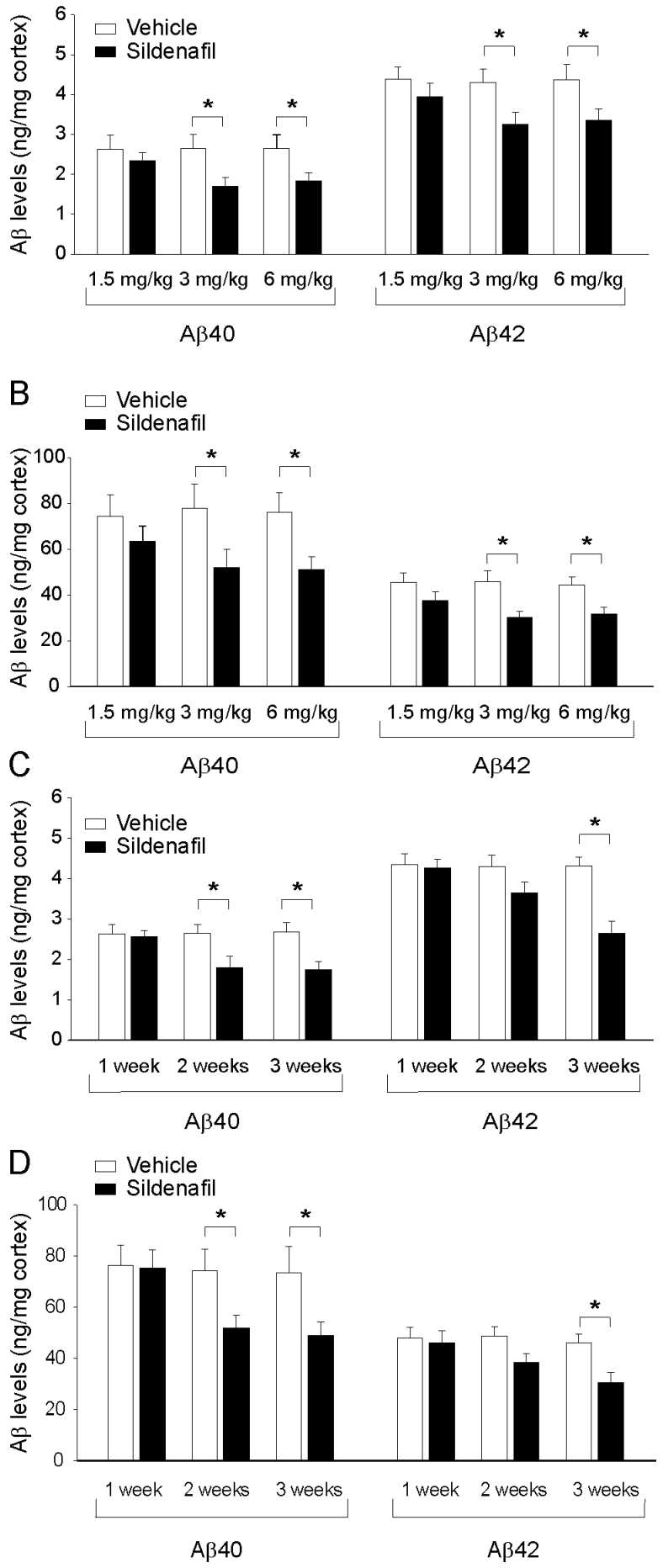

Figure 6. Sildenafil decreases $A \beta$ levels in APP/PS1 mice. $A$, Sildenafil decreases $A \beta_{40}$ and $A \beta_{42}$ levels in 3-month-old transgenic mice with a minimum effective dose of $3 \mathrm{mg} / \mathrm{kg}\left(t_{(12)}=2.32, p=\right.$ 0.039 and $t_{(12)}=2.30, p=0.04$ for $A \beta_{40}$ and $A \beta_{42}$, respectively; $n=7$ for various groups). $\boldsymbol{B}$, Daily injections of sildenafil for 3 weeks in 3 -month-old APP/PS1 mice reduce $A \beta$ levels in the same mice at $7-10$ months of age. The minimum effective dose that decreases $A \beta_{40}$ and $A \beta_{42}$ levels is $3 \mathrm{mg} / \mathrm{kg}$ $\left(t_{(12)}=2.22, p=0.04\right.$ and $t_{(12)}=2.85, p=0.01$ for $A \beta_{40}$ and $A \beta_{42}$, respectively; $n=7$ for various groups). C, The minimum time needed for $3 \mathrm{mg} / \mathrm{kg}$ sildenafil to have a positive effect on $A \beta_{40}$ is 2 weeks $\left(t_{(12)}=2.43, p=0.03\right)$, whereas values of $A \beta_{42}$ levels did not reach significance at this time ( 2 weeks: $t_{(12)}=2.22, p=0.04 ; 3$ weeks: $t_{(12)}=2.85, p=0.01 ; n=7$ for various groups). $\boldsymbol{D}$, The minimum time needed for $3 \mathrm{mg} / \mathrm{kg}$ sildenafil, administered at 3 months of age, to have a positive effect on $A \beta_{40}$ levels in the same mice at $7-8$ months of age, is 3 weeks $\left(t_{(12)}=2.33, p=0.03\right)$, whereas levels of $A \beta_{42}$ at 2 weeks are slightly above significance $\left(2\right.$ weeks: $t_{(12)}=2.02, p=0.06 ; 3$ weeks: $t_{(12)}=2.95, p=0.01 ; n=7$ for various groups). 
had been injected with $3 \mathrm{mg} / \mathrm{kg} / \mathrm{d}$ sildenafil at the age of 3 months and then left without treatment for 9-12 weeks (Fig. 6D). Thus, it is likely that a reduction in $A \beta$ levels is at the bases of the prolonged beneficial effect by sildenafil on phospho-CREB.

\section{Discussion}

The present study shows novel findings demonstrating that a treatment with the PDE5 inhibitor sildenafil rescues synaptic and memory deficits in a transgenic mouse model of amyloid deposition. Sildenafil also re-establishes the increase in phosphorylation of the transcription factor and memory molecule CREB. In addition, the inhibitor counteracts the negative effects of high levels of $\mathrm{A} \beta$ on synaptic function, memory, and CREB phosphorylation, not only immediately, but also for a prolonged period beyond the drug administration. Finally, sildenafil causes an immediate and long-lasting reduction in $\mathrm{A} \beta_{40}$ and $\mathrm{A} \beta_{42}$ levels. These findings support a model in which PDE5 inhibitors counteract the deficit in CREB phosphorylation by $\mathrm{A} \beta$, not only immediately, but also for a prolonged period of time through regulation of transcription of genes controlling $\mathrm{A} \beta$ synthesis/degradation.

A relevant finding of the present study is the reversal of the memory impairment in the APP/PS1 mouse after PDE5 inhibition. These results are in agreement with the observation that NO-mimetic molecules may reverse the cognitive impairment caused by scopolamine (Thatcher et al., 2004), or by forebrain cholinergic depletion (Bennett et al., 2007), suggesting that stimulating the NO/cGMP signal transduction system can provide new, effective treatments for cognitive disorders. With regard to the beneficial effect on memory, it is interesting to note that inhibition of PDE5 activity during a time window starting immediately after training for fear learning or after acquisition of the spatial task and ending at no more than $4 \mathrm{~h}$ after them improves learning in the transgenic animals. Nonetheless, one cannot exclude that administration of the inhibitor at other times is also beneficial against memory deficits. Moreover, given that the beneficial effect of sildenafil was observed with its injection after the training, it is likely that inhibition of PDE5 acts on memory consolidation mechanisms and not on aspects of performance, such as perception of pain or of the environment. Such modifications, in turn, might be a component of the complex physiologic changes underlying memory. Nonetheless, one cannot exclude a priori the possibility of side effects because of the profound and prolonged effect of PDE5 inhibition, and, therefore, this safetyrelated concern will need to be taken into account when developing new PDE5 inhibitors at the time of checking their toxicity.

Another discovery reported in our study is the beneficial effect of sildenafil against synaptic dysfunction in the APP/PS1 mouse. This finding is consistent with studies on slices showing that cGMP increase through the use of NO donors or cGMP analogs rescues the reduction of LTP and the inhibition of CREB phosphorylation induced by exogenous application of $\mathrm{A} \beta$ (Puzzo et al., 2005) (see also third paragraph of supplemental discussion, available at www.jneurosci.org as supplemental material). Given that altered synaptic function is a fundamental aspect in the cognitive decline of AD (Masliah, 1995), an advantage of using PDE5 inhibitors in $\mathrm{AD}$ might be that this class of compounds will counteract aspects of the disease linked to synaptic dysfunction that might be relevant to memory loss.

Decrease in A $\beta$ levels by PDE5 inhibition in transgenic mice is another important finding of our studies. This result is in agreement with the observation that the NO-releasing drug NCX-2216 reduces $\mathrm{A} \beta$ load in APP/PS1 mice (Jantzen et al., 2002). More- over, it has been found that genetic deletion of NOS2 increases $\mathrm{A} \beta$ levels in APP overexpressing mice (Colton et al., 2006). Interestingly, the decrease in $A \beta$ levels was still present after 3 to 5 months from the end of sildenafil administration. Considering that sildenafil has a short half-life, this effect might be attributable to an action on expression of genes regulating $A \beta$ production and/or clearance. CREB has been implicated in the physiologic regulation of genes whose expression results in the formation and stabilization of long-term memory, probably through the formation of new synaptic connections (Tully et al., 2003). When phospho-CREB binds to CBP, it stimulates CRE-dependent gene expression. CBP functions as a coactivator that facilitates interactions with the basal transcription machinery and catalyzes histone acetylation, causing loss in chromosomal repression and increase in the transcription of memory-associated genes. Histone acetylation can be self-perpetuating, creating a functionally stable chromatin state and thus chronic changes in the rates of specific gene expression (Battaglioli et al., 2002; Lunyak et al., 2002; Turner, 2002). Thus, an interesting hypothesis derived from our studies is that the prolonged beneficial effect of sildenafil is attributable to a permanent increase in histone acetylation. Consistent with this hypothesis, we have recently demonstrated that inhibition of histone deacetylation that is normally attributable to a group of enzymes with a reverse effect of CBP re-establishes normal LTP and memory in APP/PS1 mice (Francis et al., 2009).

The beneficial effect of sildenafil resembles many aspects of the effects of rolipram, a PDE4 inhibitor that elevates cAMP levels and therefore activates CREB through PKA (Gong et al., 2004). Moreover, several nonspecific PDE inhibitors, such as caffeine, papaverine, and isobutylmethylxanthine have been reported to improve some behavioral performance in experimental animals, probably by antagonizing adenosine receptors or by acting on intracellular $\mathrm{Ca}^{2+}$ stores (Villiger and Dunn, 1981; Randt et al., 1982; Nicholson, 1990; Nehlig et al., 1992). Nevertheless, the beneficial effect of sildenafil is likely to be specific to PDE5 inhibition, because tadalafil, a highly selective PDE5 inhibitor, reproduced the effect of sildenafil on synaptic dysfunction, whereas IC354, a selective inhibitor of PDE1, another PDE that might have been inhibited by sildenafil (selectivity ratio 180) (Daugan et al., 2003b), did not re-establish normal LTP in slices from the double transgenic mice. Moreover, differently than rolipram, which did not improve spatial working memory immediately after its administration, sildenafil immediately augmented spatial working memory. Most importantly, a striking difference between the effect of sildenafil and those of rolipram is that the former reduced $A \beta$ levels in the brains of APP/PS1 mice, whereas the latter did not affect $\mathrm{A} \beta$ load.

When proposing a new class of drugs as therapeutic agents, it is imperative to consider their possible side effects. This might have determined the failure of PDE4 inhibitors to enhance memory. An advantage of using PDE5 inhibitors is that their side effects are known, as they have already been used for many years, such that the FDA has recently authorized the daily use of tadalafil. Priapism has been reported to occur in a few cases after the intake of PDE5 inhibitors. However, the current view about the cause of priapism is that it is likely because of a dysregulation of PDE5 function after downregulation of the NO pathway (Champion et al., 2005) - a phenomenon that is also caused by $\mathrm{A} \beta$ increase (Puzzo et al., 2005) — such that, paradoxically, PDE5 inhibitors have been proposed as therapeutic agents against priapism (Burnett et al., 2006; Rajfer et al., 2006). Additional adverse events of the PDE5 inhibitors include mild vasodilatory effects 
such as headache, flushing, dyspepsia, and nasal congestion or rhinitis, which might warrant caution in proposing PDE5 inhibitors as $\mathrm{AD}$ agents. However, although $\mathrm{A} \beta$ is primarily accumulating in the CNS, $A \beta$ is also present in the blood of patients affected by $\mathrm{AD}$ and other neurological disorders characterized by abnormal A $\beta$ production (Basun et al., 2002; Andreasen et al., 2003). Intriguingly, systemic $A \beta$ potentiates vasoconstriction not only in cerebral vasculature but also in other districts of the vascular system (Pasquier and Leys, 1998; Khalil et al., 2002; Kalaria, 2003; Suhara et al., 2003; Gentile et al., 2004; Price et al., 2004; Smith et al., 2004). Moreover, hypertension is often associated with AD (Pasquier and Leys, 1998; Gentile et al., 2004; Price et al., 2004). Thus, it is very appealing to think that PDE5 inhibitors might counteract not only CNS symptoms but also vascular symptoms that often affect AD patients.

Our findings strongly support the hypothesis that inhibition of PDE5 can be beneficial against cognitive loss in AD. However, none of the existing commercially available inhibitors, including sildenafil, are optimized for the CNS. A good CNS drug should have high specificity and potency, as well as good pharmacokinetic, bioavailability, and CNS penetration, and finally should be safe. For instance, sildenafil is reported to clearly cross the BBB (FDA, 1998) and has an $\mathrm{IC}_{50}$ against PDE5 of $6.0 \mathrm{~nm}$ and an in vivo half-life of $0.4 \mathrm{~h}$ in rodents ( $\sim 4 \mathrm{~h}$ in humans) (Walker et al., 1999; Daugan et al., 2003b). However, the selectivity ratio for PDE1, which is expressed in myocardium and blood vessels in addition to the brain and may result in mild vasodilatatory effects, is 180, and that for PDE6, which is expressed only in retina and can transiently disturb vision, is equal to 12 (Corbin and Francis, 2002; Daugan et al., 2003a). Evidence for vardenafil's ability to cross the BBB is indirect (Prickaerts et al., 2004), and even if its $\mathrm{IC}_{50}$ against PDE5 is $0.17 \mathrm{nM}$, the selectivity ratio for PDE6 is equal to 3.5 (Saenz de Tejada et al., 2001; Zhang et al., 2005). Tadalafil, finally, is not likely to cross the BBB. Thus, our findings should be interpreted as proof of concept in favor of developing new PDE5 inhibitors that are optimized for the CNS. Indeed, our laboratories have launched a program to develop new PDE5 inhibitors that fit all the criteria described above and can be used in $\mathrm{AD}$ patients.

\section{References}

Andreasen N, Sjögren M, Blennow K (2003) CSF markers for Alzheimer's disease: total tau, phospho-tau and Abeta42. World J Biol Psychiatry 4:147-155.

Baratti CM, Boccia MM (1999) Effects of sildenafil on long-term retention of an inhibitory avoidance response in mice. Behav Pharmacol 10:731-737.

Basun H, Nilsberth C, Eckman C, Lannfelt L, Younkin S (2002) Plasma levels of Abeta42 and Abeta40 in Alzheimer patients during treatment with the acetylcholinesterase inhibitor tacrine. Dement Geriatr Cogn Disord 14:156-160.

Battaglioli E, Andrés ME, Rose DW, Chenoweth JG, Rosenfeld MG, Anderson ME, Mandel G (2002) REST repression of neuronal genes requires components of the hSWI.SNF complex. J Biol Chem 277:41038-41045.

Bennett BM, Reynolds JN, Prusky GT, Douglas RM, Sutherland RJ, Thatcher GR (2007) Cognitive deficits in rats after forebrain cholinergic depletion are reversed by a novel NO mimetic nitrate ester. Neuropsychopharmacology 32:505-513.

Burnett AL, Bivalacqua TJ, Champion HC, Musicki B (2006) Long-term oral phosphodiesterase 5 inhibitor therapy alleviates recurrent priapism. Urology 67:1043-1048.

Champion HC, Bivalacqua TJ, Takimoto E, Kass DA, Burnett AL (2005) Phosphodiesterase-5A dysregulation in penile erectile tissue is a mechanism of priapism. Proc Natl Acad Sci U S A 102:1661-1666.

Colton CA, Vitek MP, Wink DA, Xu Q, Cantillana V, Previti ML, Van Nostrand WE, Weinberg JB, Weinberg B, Dawson H (2006) NO synthase 2
(NOS2) deletion promotes multiple pathologies in a mouse model of Alzheimer's disease. Proc Natl Acad Sci U S A 103:12867-12872.

Corbin JD, Francis SH (2002) Pharmacology of phosphodiesterase-5 inhibitors. Int J Clin Pract 56:453-459.

Daugan A, Grondin P, Ruault C, Le Monnier de Gouville AC, Coste H, Kirilovsky J, Hyafil F, Labaudinière R (2003a) The discovery of tadalafil: a novel and highly selective PDE5 inhibitor. 1: 5,6,11,11a-tetrahydro-1Himidazo[1', 5':1,6]pyrido[3,4-b] indole-1,3(2H)-dio ne analogues. J Med Chem 46:4525-4532.

Daugan A, Grondin P, Ruault C, Le Monnier de Gouville AC, Coste H, Linget JM, Kirilovsky J, Hyafil F, Labaudinière R (2003b) The discovery of tadalafil: a novel and highly selective PDE5 inhibitor. 2: 2,3,6,7,12,12ahexahydropyrazino $\left[1^{\prime}, 2^{\prime}: 1,6\right]$ pyrido[3,4-b]indole-1,4-dione analogues. J Med Chem 46:4533-4542.

Diamond DM, Park CR, Heman KL, Rose GM (1999) Exposing rats to a predator impairs spatial working memory in the radial arm water maze. Hippocampus 9:542-552.

FDA (1998) Viagra tablets (sildenafil citrate). Review and evaluation of pharmacology and toxicology data. Report from the Division of Cardiorenal Drug Products (HFD-10). Center for Drug Evaluation and Research. In: Food and Drug Administration, pp 121-122. Washington, DC.

Francis IY, Fà M, Ashraf H, Zhang H, Staniszewski A, Latchman DS, Arancio O (2009) Dysregulation of histone acetylation in the APP/PS1 mouse model of Alzheimer's disease. J Alzheimers Dis, in press.

Gentile MT, Vecchione C, Maffei A, Aretini A, Marino G, Poulet R, Capobianco L, Selvetella G, Lembo G (2004) Mechanisms of soluble betaamyloid impairment of endothelial function. J Biol Chem 279:48135-48142.

Gong B, Vitolo OV, Trinchese F, Liu S, Shelanski M, Arancio O (2004) Persistent improvement in synaptic and cognitive functions in an Alzheimer mouse model after rolipram treatment. J Clin Invest 114:1624-1634.

Gong B, Cao Z, Zheng P, Vitolo OV, Liu S, Staniszewski A, Moolman D, Zhang H, Shelanski M, Arancio O (2006) Ubiquitin hydrolase Uch-L1 rescues beta-amyloid-induced decreases in synaptic function and contextual memory. Cell 126:775-788.

Jantzen PT, Connor KE, DiCarlo G, Wenk GL, Wallace JL, Rojiani AM, Coppola D, Morgan D, Gordon MN (2002) Microglial activation and $\beta$-amyloid deposit reduction caused by a nitric oxide-releasing nonsteroidal anti-inflammatory drug in amyloid precursor protein plus presenilin-1 transgenic mice. J Neurosci 22:2246-2254.

Kalaria RN (2003) Vascular factors in Alzheimer's disease. Int Psychogeriatr 15 [Suppl 1]:47-52.

Khalil Z, Poliviou H, Maynard CJ, Beyreuther K, Masters CL, Li QX (2002) Mechanisms of peripheral microvascular dysfunction in transgenic mice overexpressing the Alzheimer's disease amyloid Abeta protein. J Alzheimers Dis 4:467-478.

Lu YF, Kandel ER, Hawkins RD (1999) Nitric oxide signaling contributes to late-phase LTP and CREB phosphorylation in the hippocampus. J Neurosci 19:10250-10261.

Lunyak VV, Burgess R, Prefontaine GG, Nelson C, Sze SH, Chenoweth J, Schwartz P, Pevzner PA, Glass C, Mandel G, Rosenfeld MG (2002) Corepressor-dependent silencing of chromosomal regions encoding neuronal genes. Science 298:1747-1752.

Masliah E (1995) Mechanisms of synaptic dysfunction in Alzheimer's disease. Histol Histopathol 10:509-519.

Morgan D, Diamond DM, Gottschall PE, Ugen KE, Dickey C, Hardy J, Duff K, Jantzen P, DiCarlo G, Wilcock D, Connor K, Hatcher J, Hope C, Gordon M, Arendash GW (2000) A beta peptide vaccination prevents memory loss in an animal model of Alzheimer's disease. Nature 408:982-985.

Nehlig A, Daval JL, Debry G (1992) Caffeine and the central nervous system: mechanisms of action, biochemical, metabolic and psychostimulant effects. Brain Res Brain Res Rev 17:139-170.

Nicholson CD (1990) Pharmacology of nootropics and metabolically active compounds in relation to their use in dementia. Psychopharmacology 101:147-159.

Pasquier F, Leys D (1998) Blood pressure and Alzheimer's disease. Rev Neurol 154:743-751.

Phillips RG, LeDoux JE (1992) Differential contribution of amygdala and hippocampus to cued and contextual fear conditioning. Behav Neurosci 106:274-285.

Price JM, Hellermann A, Hellermann G, Sutton ET (2004) Aging enhances 
vascular dysfunction induced by the Alzheimer's peptide beta-amyloid. Neurol Res 26:305-311.

Prickaerts J, de Vente J, Honig W, Steinbusch HW, Blokland A (2002a) cGMP, but not cAMP, in rat hippocampus is involved in early stages of object memory consolidation. Eur J Pharmacol 436:83-87.

Prickaerts J, van Staveren WC, Sik A, Markerink-van Ittersum M, Niewöhner U, van der Staay FJ, Blokland A, de Vente J (2002b) Effects of two selective phosphodiesterase type 5 inhibitors, sildenafil and vardenafil, on object recognition memory and hippocampal cyclic GMP levels in the rat Neuroscience 113:351-361.

Prickaerts J, Sik A, van Staveren WC, Koopmans G, Steinbusch HW, van der Staay FJ, de Vente J, Blokland A (2004) Phosphodiesterase type 5 inhibition improves early memory consolidation of object information. Neurochem Int 45:915-928.

Puzzo D, Vitolo O, Trinchese F, Jacob JP, Palmeri A, Arancio O (2005) Amyloid- $\beta$ peptide inhibits activation of the nitric oxide/cGMP/cAMPresponsive element-binding protein pathway during hippocampal synaptic plasticity. J Neurosci 25:6887-6897.

Rajfer J, Gore JL, Kaufman J, Gonzalez-Cadavid N (2006) Case report: Avoidance of palpable corporal fibrosis due to priapism with upregulators of nitric oxide. J Sex Med 3:173-176.

Randt CT, Judge ME, Bonnet KA, Quartermain D (1982) Brain cyclic AMP and memory in mice. Pharmacol Biochem Behav 17:677-680.

Saenz de Tejada I, Angulo J, Cuevas P, Fernández A, Moncada I, Allona A, Lledó E, Körschen HG, Niewöhner U, Haning H, Pages E, Bischoff E (2001) The phosphodiesterase inhibitory selectivity and the in vitro and in vivo potency of the new PDE5 inhibitor vardenafil. Int J Impot Res 13:282-290.

Schenk F, Morris RG (1985) Dissociation between components of spatial memory in rats after recovery from the effects of retrohippocampal lesions. Exp Brain Res 58:11-28.

Selkoe DJ (2002) Alzheimer's disease is a synaptic failure. Science 298:789-791

Silva AJ, Kogan JH, Frankland PW, Kida S (1998) CREB and memory. Annu Rev Neurosci 21:127-148.

Smith CC, Stanyer L, Betteridge DJ (2004) Soluble beta-amyloid (A beta) 40 causes attenuation or potentiation of noradrenaline-induced vasoconstriction in rats depending upon the concentration employed. Neurosci Lett 367:129-132.

Snyder PB, Esselstyn JM, Loughney K, Wolda SL, Florio VA (2005) The role of cyclic nucleotide phosphodiesterases in the regulation of adipocyte lipolysis. J Lipid Res 46:494-503.

Suhara T, Magrané J, Rosen K, Christensen R, Kim HS, Zheng B, McPhie DL, Walsh K, Querfurth H (2003) Abeta42 generation is toxic to endothelial cells and inhibits eNOS function through an Akt/GSK-3beta signalingdependent mechanism. Neurobiol Aging 24:437-451.

Terrett NK, Bell AS, Brown D, Ellis P (1996) Sildenafil (Viagra ${ }^{\mathrm{TM}}$ ), a potent and selective inhibitor of type 5 cGMP phosphodiesterase with utility for the treatment of male erectile dysfunction. Bioorg Med Chem Lett 6:1819-1824.

Thatcher GR, Bennett BM, Dringenberg HC, Reynolds JN (2004) Novel nitrates as NO mimetics directed at Alzheimer's disease. J Alzheimers Dis 6:S75-S84.

Trinchese F, Liu S, Battaglia F, Walter S, Mathews PM, Arancio O (2004) Progressive age-related development of Alzheimer-like pathology in APP/ PS1 mice. Ann Neurol 55:801-814.

Tully T, Bourtchouladze R, Scott R, Tallman J (2003) Targeting the CREB pathway for memory enhancers. Nat Rev Drug Discov 2:267-277.

Turner BM (2002) Cellular memory and the histone code. Cell 111:285-291.

Van Staveren WC, Steinbusch HW, Markerink-Van Ittersum M, Repaske DR, Goy MF, Kotera J, Omori K, Beavo JA, De Vente J (2003) mRNA expression patterns of the cGMP-hydrolyzing phosphodiesterases types 2,5 , and 9 during development of the rat brain. J Comp Neurol 467:566-580.

van Staveren WC, Steinbusch HW, Markerink-van Ittersum M, Behrends S, de Vente J (2004) Species differences in the localization of cGMPproducing and NO-responsive elements in the mouse and rat hippocampus using cGMP immunocytochemistry. Eur J Neurosci 19:2155-2168.

Villiger JW, Dunn AJ (1981) Phosphodiesterase inhibitors facilitate memory for passive avoidance conditioning. Behavioral and neural biology 31:354-359.

Vitolo OV, Sant'Angelo A, Costanzo V, Battaglia F, Arancio O, Shelanski M (2002) Amyloid beta -peptide inhibition of the PKA/CREB pathway and long-term potentiation: reversibility by drugs that enhance cAMP signaling. Proc Natl Acad Sci U S A 99:13217-13221.

Walker DK, Ackland MJ, James GC, Muirhead GJ, Rance DJ, Wastall P, Wright PA (1999) Pharmacokinetics and metabolism of sildenafil in mouse, rat, rabbit, dog and man. Xenobiotica 29:297-310.

Zhang X, Feng Q, Cote RH (2005) Efficacy and selectivity of phosphodiesterasetargeted drugs in inhibiting photoreceptor phosphodiesterase (PDE6) in retinal photoreceptors. Invest Ophthalmol Vis Sci 46:3060-3066. 